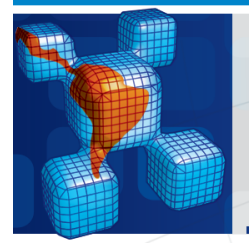

\title{
Fuzzy logic for structural system control
}

\begin{abstract}
This paper provides some information and numerical tests that aims to investigate the use of a Fuzzy Controller applied to control systems. Some advantages are reported regarding the use of this controller, such as the characteristic ease of implementation due to its semantic feature in the statement of the control rules. On the other hand, it is also hypothesized that these systems have a lower performance loss when the system to be controlled is nonlinear or has time varying parameters. Numerical tests are performed using modal LQR optimal control and Fuzzy control of non-collocated systems with full state feedback in a twodimensional structure. The paper proposes a way of designing a controller that may be a supervisory Fuzzy controller for a traditional controller or even a fuzzy controller independent from the traditional control, consisting on individual mode controllers. Some comments are drawn regarding the performance of these proposals in a number of arrangements. Keywords
\end{abstract}

fuzzy sets, vibration control, heuristic algorithms.

\section{Herbert Martins Gomes}

${ }^{a}$ Department of Mechanical Engineering, Federal University of Rio Grande do Sul, RS Brazil

Received 09 Jun 2011; In revised form 17 Feb 2012

* Author email: herbert@mecanica.ufrgs.br

\section{INTRODUCTION}

In a broad sense, fuzziness is the opposite of precision. Everything that cannot be defined precisely (that is, according to some broadly accepted criteria or norms of precision) and everything that has no clearly described boundaries in space or time is considered a bearer of fuzziness. As stated by Dimitrov [5], Fuzzy logic is also a product of rational thinking and entirely subjected to its 'IF...THEN' rules of inference. According to him it will work satisfactorily 'up to a degree' when dealing with the fuzziness of human perceptions and words and has been used to put into the computer's memory as much as possible of the experts' practical knowledge and competence, then using them for the purpose of designing and controlling intelligent engineering systems and robots. Moreover, the use of different degrees of 'truth', in parallel, creates a fuzzy framework, which is more adequate to the way people express their perceptions in words and therefore more efficient in using these perceptions in computercontrolled engineering and robotic scenarios. Although fuzzy logic 'softens' the problem of choice by replacing 'either...or' with 'as well as', it remains rigidly attached to strictly pre- 
determined sets of alternatives (inputs, outputs, goals, criteria) and lists of rules describing the mutual relations between the alternatives.

If the set of alternatives consists only of $\mathrm{A}$ and $\mathrm{B}$, with fuzzy logic we can never generate $\mathrm{C}$; it is the human operator who, based on his or her experience, can generate (discover, create) new decisions.

Fuzzy logic needs a full description of the rules of relations between the inputs and outputs that can occur in a considered engineering context; when complexity increases, the list of rules may become extremely large and may need a great deal of expert information (not easily available). Fuzzy logic resembles the way of thinking of actors left with an agreed set of decision options, a list of rules of behavior and of instructions how to use them 'fuzzily' so that to solve a specific problem; the actors are given no ideas how to go beyond this set of options and to look for other solutions which might be better. And even if they have information about something 'better', they have not been taught how to free themselves from all those fuzzy rules and instructions that keep the control system running.

Fuzzy logic was first introduced by Lotfi A. Zadeh [17] as natural extension in the classical notion of set theory. Unlike the classical theory in which elements belong or not to given set, this theory allows the degree of belongness of a particular element can be attributed in a gradual way.

Fuzzy logic allows you to develop expert systems using linguistic variables to create a rule base. Linguistic expressions are typical of human nature on taking decisions. For example: "If it is warm I will turn the air conditioning at maximum". Warm does not mean a particular value of temperature and power, but may assume a considerable range of values depending on persons' reasoning. Different people may also have different meanings to the same linguistic concepts. In his works, Zadeh stated the so-called "Principle of Incompatibility", which can be verified in other areas of science. He said: "The closer one looks at the real world problem, the fuzzier becomes its solution", indicating that the treatment of systems in much detail can lead to solutions that are diffuse. In fact, as the complexity of a system increases, our ability to make accurate statements of the behavior of the system significantly decreases until it reaches a limit beyond which precision and significance become mutually exclusive characteristics.

\subsection{Advantages of Fuzzy controllers over conventional ones.}

According to Al-Odienat et al [2], generally speaking, Fuzzy controllers are cheaper to develop, cover a wide range of operating conditions and they are readily adapted in terms of natural language when compared to conventional controllers. Self-organizing Fuzzy controllers can automatically refine the initial fuzzy rules. The Fuzzy controller design should allow the flexibility to modify the control, since the involved systems, in practice, are generally complex with time varying nonlinearities with ill-defined dynamics. Thus, conventional control methods based on the theory of linear systems usually linearize nonlinear systems before being used. This is not a guarantee of good performance in practice [13]. Also, most of the controllers are developed based on precise mathematical models of the system. In fact, some systems are difficult to be accurately modeled with rigorous mathematical models and this has motivated

Latin American Journal of Solids and Structures 9(2012) 111 - 129 
the interest in the use of Fuzzy Controllers. Another advantage is that the Fuzzy controller is adjustable and easily understood by human experts as the knowledge of the control placed on the rule base is semantic.

In short, we can highlight the advantages of using fuzzy controllers as:

- They are conceptually easy to understand: the concepts behind are very simple and basic;

- They are flexible: they allow adding functionality to existing Fuzzy systems just adding new knowledge on the pre-existing rule base;

- They are tolerant to imprecise data: precision errors or randomness of measurements has little influence on system performance;

- They can model nonlinear systems with arbitrary complexity: this can be done by systems such as "Adaptive Neuro-Fuzzy Inference Systems";

- They can be constructed based on the knowledge of experts and system's behavior;

- They can be easily mixed with the traditional control systems, offering increased performance;

- They are based on natural human language, which facilitates the addition, modification of new rules, exceptions and new behaviors to pre-existing Fuzzy systems.

The control of systems using traditional methodologies face problems when dealing with non-linearity, poor mathematical definition of the problem, changes and uncertainty in the system parameters as well. This can reduce performance or even unsettle the control system designed with traditional methodologies. In this sense, control systems that are robust enough to adapt and adjust to these changes are desirable [6].

In a feedback control system the error signal $e(t)=r-y(t)$ is the input to the Fuzzy controller which adjusts the control signal $u(t)$ accordingly so that the sign of the error tends to zero.

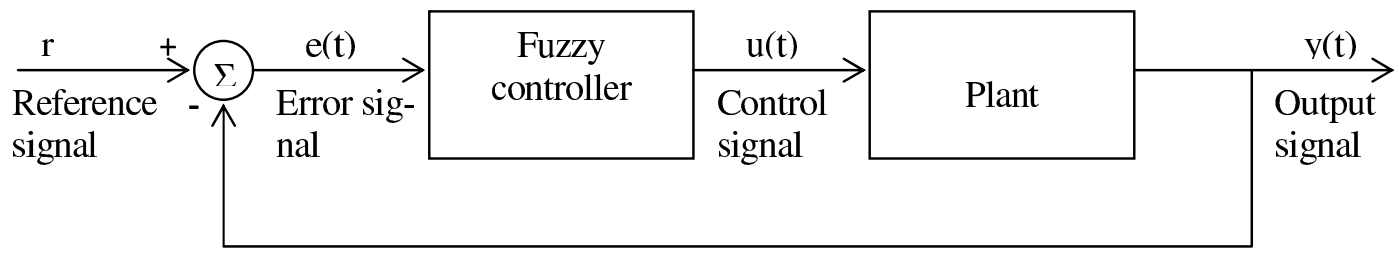

Figure 1 Closed loop control system with fuzzy logic. 


\section{$1.2 \quad$ Fuzzy controller parts}

According to Passino [10], a Fuzzy Controller has 4 basic elements, namely:

- A set of rules, which contain a quantification of diffuse linguistic description of "experts" on how to achieve good control;

- An inference engine, which "emulates" the decision of the "expert" knowledge based on how good should be the control for a particular plant;

- A fuzzification interface, which converts controller inputs into information that the inference engine can easily use to activate and apply the rule base;

- A defuzzification interface which converts the conclusions reached by the inference mechanism into output values to control the process.

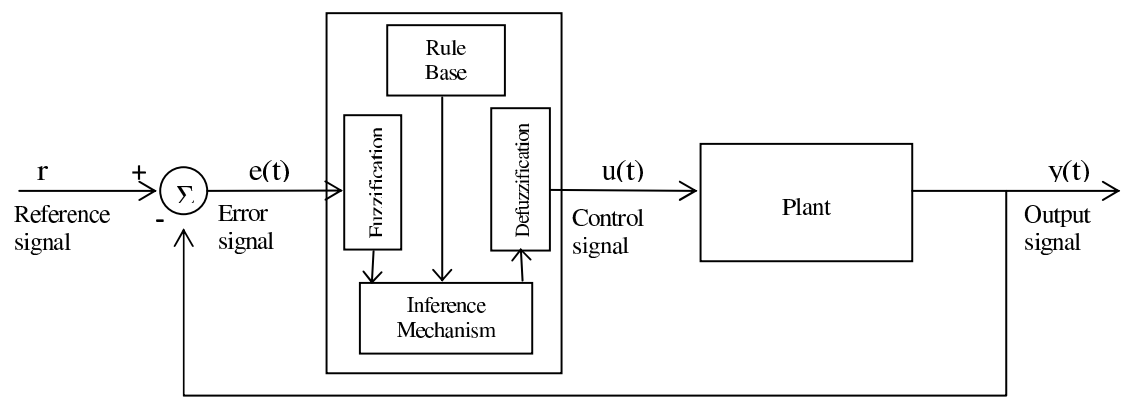

Figure 2 Detail of a control system with a Fuzzy controller.

A Fuzzy controller may have, in addition to the error signal of the plant output, the derivative or the integral of the error, with entries similar to a traditional PID controller (Proportional, Integral and Derivative). Using a PD (Proportional Derivative) type Fuzzy Controller, the rule base (control laws) can be simply understood by looking at the case of control of the response of a system variable $y$ for a given reference value $r$ as indicated by Figure 3.

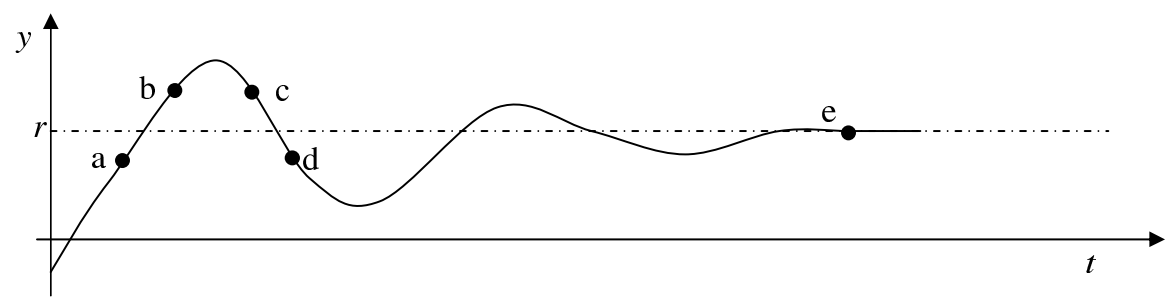

Figure 3 Output control signal of a system for a given reference value $r$.

Defining the error by $e(t)=r-y(t)$, then $d e / d t=\dot{e}(t)=-\dot{y}(t)$, each of the points indicated in the previous Figure can generate rules for the PD Fuzzy controller action. It will be $4\left(2^{2}\right)$

Latin American Journal of Solids and Structures 9(2012) $111-129$ 
rules and one more rule for turning off the controller in case the error and the derivative of error are null.

- Point a : If $e(t)>0$ and $\dot{e}(t)<0$ then the control system should hold previous action

- Point b: If $e(t)<0$ and $\dot{e}(t)<0$ then the control system should change previous action

- Point c: If $e(t)<0$ and $\dot{e}(t)>0$ then the control system should hold previous action

- Point d: If $e(t)>0$ and $\dot{e}(t)>0$ then the control system should change previous action

- Point e: If $e(t)=0$ or $\dot{e}(t)=0$ then the control system should cancel the action

Similar rules may be assembled referred to an integral term $\int e(t) d t$ and may generate a total of $8\left(2^{3}\right)$ rules for the PID Controller [8]. Obviously, all the inequalities can be transformed to linguistic form with levels of diffuse gradation for the boundaries of what is positive or negative. The error $e(t)$, for example, can be "discretized" in levels such as NB (negative big), NM (negative medium), Z (zero), PM (positive medium) and PB (positive big).

\subsection{Fuzzy sets}

Unlike the traditional theory, which classifies the elements in a decisive manner belonging or not to a set (0 or 1), Fuzzy Logic has the ability to classify all those elements into a so-called degree of belongness by a membership function (between 0 and 1 ).

Some of the membership functions that are used for the variable's fuzzification are the triangular membership function and the trapezoidal membership function depicted in Figure 4 .
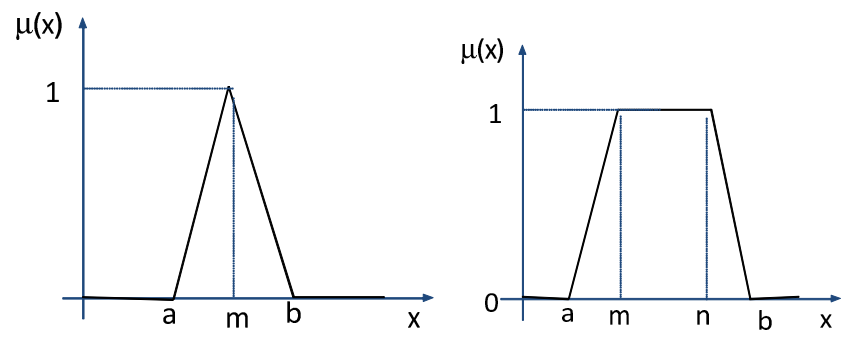

Figure 4 Triangular and trapezoidal membership function.

Similar to the traditional set theory, fuzzy sets have rules and definitions for the operations with the sets, like Union, Intersection, Product of fuzzy sets, etc. More details regarding this definition can be found in Jantzen [6]. Generally speaking, one can say that the traditional set theory is a special case of the theory of fuzzy sets where the membership function presents a sharp (crisp) membership function like a step function. 


\subsection{Aggregation of the propositions and the implications of the fuzzy rule base}

Given a rule base of a fuzzy system, each of these rules will have propositions and implications. The number of propositions can be variable depending on the problem:
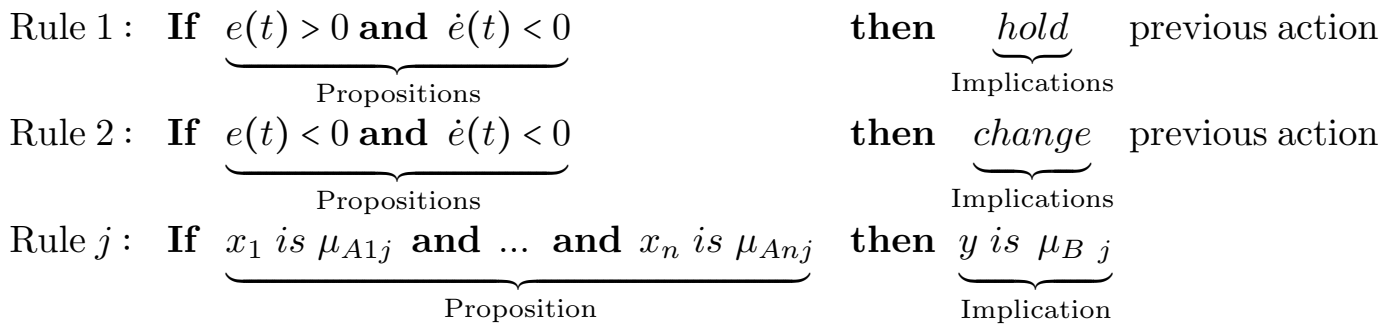

where $x_{1}, . ., x_{n}$, are the input variables, $\mu_{A 1 j}$ and $\mu_{B j}$ are fuzzy sets for fuzzification of input variables $\left(x_{i}\right)$ and the output variables $(y)$.

There are several ways to add the propositions and the implications on the rule base of a Fuzzy system. This paper uses the Mandani Method [9], which is the method widely used and applied in the literature. In this case, for the aggregation of propositions, one has:

$$
\phi\left(<\ldots>, \mu_{A}(X)\right)=<\text { number }>\wedge \mu_{A}(X)=\min \left(\text { number }, \mu_{A}(X)\right)
$$

For the aggregation of the implications, one has:

$$
\phi\left(\mu_{A}(X), \mu_{B}(X), \ldots\right)=\mu_{A}(X) \vee \mu_{B}(X) \vee \ldots=\max \left(\mu_{A}(X), \mu_{B}(X), \ldots\right)
$$

More details can be found in Pedrycz and Gomide [11].

\section{FUZZY LOGIC APPLIED TO CONTROL SYSTEMS}

A hybrid smart composite beam actuated by piezoceramics and electro-rheological fluid actuators was investigated by Takawa et al [15]. It is said that a fuzzy controller containing the two actuators was chosen because the application of the linear control theory to the vibration controls would be difficult due to intense non-linearity of the actuators. The developed vibration control system with a fuzzy controller was verified by simulations and experiments. The used model was a cantilever beam. A Takagi-Sugeno (T-S) Method is used for the aggregation of the rules. As output for each rule, a linear and a discrete linear equation of vibration of the tip of the composite beam is proposed assuming first mode vibration, since excitation provided by a shaker of the clamped end was sinusoidal. So, a previous identification of the parameters used in this equation was performed in order to latter use the Controller. Results of experimental measurements and numerical tests are presented to tip deflection history. No metric is proposed to measure the effectiveness of the proposed methodology.

In 2000, Teng et al [16] presented a very simple study on the application of fuzzy theory to structural active control. The used example in the study was a simple cantilever beam, modelled as a discrete 5 equally spaced beam finite element. The input variables used for the controller were the deflection and velocity of the tip of the beam, and the output variable 
was the force used to control vibrations applied at the same site (collocated system). All variables were discretized with five membership functions. For the aggregation of implications it was used the Mandani Method. There were no "metric" for comparisons and the results were presented only in terms of displacements and velocity history. Some parametric studies regarding overlapping of the membership functions were conducted in order to obtain the best Fuzzy control method. They concluded that an overlapping ratio of 0.3 produced better control effects than 0.5 overlapping ratio. Finally, they concluded that the negative effects of vibration in the structure can be successfully suppressed using this type of controller.

An active modal-fuzzy control method for seismic response reduction is proposed by Choi et al [4]. The controller was designed in modal space. It used a Kalman Filter to estimate modal states and a low-pass filter used to eliminate spillover effects in the applications of control forces. The advantages presented in the paper were based on the fact that working in modal space the size of the problem can be reduced, but nothing is said neither the way the Fuzzy controller uses modal state-variables nor the way the gain matrix is evaluated or updated during the process. The aggregation method used was the Takagi-Sugeno method [14]. It was controlled just the first mode. An infinity horizon performance index is proposed in order to compare the results. The propose fuzzy controller Type-A, that uses two inputs (first mode displacement coordinates and first mode velocity coordinate, each with five membership function and one output variable, the control force), presented better results than a traditional LQR controller. All the results presented regarding a numerical simulation of historical earthquakes showed that the proposed controller can benefit seismic response reduction in civil structures.

In 2007, Zhao et al [18] presented a PID control method for a two stage vibration isolation system. In fact, according to the rule-base presented by the authors, the proposed controller should be labelled as a PD-Fuzzy controller since it used just the error and the derivative of error as input values. All variables were discretized with 7 fuzzy sets. All the control was on the state space assuming a full-state feedback control and the control force was applied in just one of the degree of freedoms. They presented graphs of acceleration history and PSD (Power Spectral Density) of the acceleration levels for one of the degree of freedoms that showed a significant reduction in vibrations. Finally they concluded, based on numerical results, that the method is effective to improve the vibration isolation.

Ahmad [1] presented comparisons between LQR and PD Fuzzy controllers for an angular position control of flexible manipulator. The performance of the controllers was examined in terms of vibration suppression and disturbances cancelation. The numerical example showed that the effect of the disturbances in the system could successfully be handled by both LQR and PD-Fuzzy controller. The Fuzzy controller was designed with two input variables (hub angle and velocity) and one output (torque). All of the variables were discretized with five fuzzy sets. As expected, just the first mode was controlled. The aggregation method used was Mandani type, and the number of rules to tune the controller was only 11, instead of the expected $25\left(5^{2}\right)$. Graphs of the modal displacements and the PSD of modal displacements with LQR controller and Fuzzy controller were presented. Nothing is said regarding the control forces. 


\section{TRADITIONAL LINEAR QUADRATIC REGULATOR CONTROL (LQR)}

According to Preaumont [12], the equation representing the dynamic behavior of a linear system may be written as:

$$
M \ddot{q}+D \dot{q}+K q=F u
$$

where $\mathbf{M}, \mathbf{K}$ and $\mathbf{D}$ are the mass, stiffness and damping matrix respectively, $\boldsymbol{q}=\left\{q_{1}, q_{2}, \ldots, q_{n}\right\}^{\text {'T }}$ is the displacement vector and $\dot{\boldsymbol{q}}$ and $\ddot{\boldsymbol{q}}$ the velocity and acceleration vectors respectively, $\mathbf{F}$ is the load action influence matrix and $\mathbf{u}$ is the load action vector (control forces) applied by the actuators, given by:

$$
\boldsymbol{u}=\left\{\begin{array}{c}
u_{1} \\
u_{2} \\
\vdots \\
u_{n}
\end{array}\right\}
$$

Adopting the state-space representation of the dynamic of the system as $\boldsymbol{x}=\{\boldsymbol{q} \dot{\boldsymbol{q}}\}^{T}$, the following equation can be written [12]:

$$
\begin{aligned}
& \dot{x}=A x+B u \\
& y=C x+D u
\end{aligned}
$$

where $\mathbf{A}, \mathbf{B}, \mathbf{C}$ and $\mathbf{D}$ are the state, input, output and feed through matrices respectively. Matrices $\mathbf{C}$ and $\mathbf{D}$ depend on the combination of the desired output (frequently just those that can be measured) and the positioning of the actuators in the structure. For matrices $\mathbf{A}$ and $\mathbf{B}$, the following relations are valid:

$$
\boldsymbol{A}=\left[\begin{array}{cc}
\mathbf{0} & \boldsymbol{I} \\
-\boldsymbol{M}^{-1} \boldsymbol{K} & -\boldsymbol{M}^{-1} \boldsymbol{D}
\end{array}\right] \quad \text { and } \quad \boldsymbol{B}=\left[\begin{array}{c}
\mathbf{0} \\
\boldsymbol{M}^{-1} \boldsymbol{F}
\end{array}\right]
$$

In this example, since it was assumed a full state feedback, matrices $\mathbf{C}$ and $\mathbf{D}$ were defined as:

$$
\boldsymbol{C}=\boldsymbol{I} \quad \text { and } \quad \boldsymbol{D}=\mathbf{0}
$$

where $\mathbf{I}$ is the identity matrix. The output vector $\mathbf{y}$, in this case, is simply given by $\boldsymbol{y}=\{q \dot{q}\}^{T}$.

For optimal control, it is defined a linear functional to be minimized in order to achieve minimal value [7]:

$$
J=\frac{1}{2} \int_{0}^{\infty}\left(x^{T} Q x+u^{T} R u\right) d t
$$

where $\mathbf{Q}$ is the weighting matrix for a combination of state-variables to be minimized and $\mathbf{R}$ is the weighting function for the acting control loads. Based on this definition, the functional $\boldsymbol{J}$ minimizes both state-variable and control forces. The control force that minimizes the function can be stated in the following form: 


$$
\boldsymbol{u}=-\boldsymbol{G} \boldsymbol{x}
$$

where $\mathbf{G}$ is the gain matrix given by:

$$
\boldsymbol{G}=-\boldsymbol{R}^{-1} \boldsymbol{B}^{T} \boldsymbol{S}
$$

where matrix $\mathbf{S}$ is the Ricatti matrix, obtained from the solution of the Algebraic Ricatti Equation(ARE) assuming that the steady state condition is attained. The ARE is defined as:

$$
-\dot{S}=\boldsymbol{S A}+\boldsymbol{A}^{T} \boldsymbol{S}-\boldsymbol{S} \boldsymbol{B} \boldsymbol{R}^{-1} \boldsymbol{B}^{T} \boldsymbol{S}+\boldsymbol{Q}
$$

which is solved for $\mathbf{S}$. Taking into account the steady-state condition at $t \rightarrow \infty, \dot{S} \rightarrow \mathbf{0}$, this follows:

$$
0=S A+\mathrm{A}^{\mathrm{T}} \mathrm{S}-S B R^{-1} B^{\mathrm{T}} S+Q
$$

There are several methods to solve this equation and the Potter method is the used method [3] in this paper. Remembering that $\boldsymbol{y}=\boldsymbol{C} \boldsymbol{x}+\boldsymbol{D} \boldsymbol{u}$ and $\boldsymbol{D}=\mathbf{0}$, one can state that equation (13) is equivalent to:

$$
\text { Minimize } J^{*}=\frac{1}{2} \int_{0}^{\infty}\left(\boldsymbol{y}^{T} \boldsymbol{Q}^{*} \boldsymbol{y}+\boldsymbol{u}^{T} \boldsymbol{R} \boldsymbol{u}\right) d t
$$

where $\boldsymbol{Q}^{*}=\boldsymbol{C}^{-1} \boldsymbol{Q} \boldsymbol{C}$. Therefore, one can use the same procedure to evaluate the Ricatti equation to solve the control problem minimizing the output variables instead of state-space variables.

\subsection{LQR modal control}

In the case of modal control, one starts with the approximation $\boldsymbol{q}=\boldsymbol{\Phi} \boldsymbol{\eta}$, where $\boldsymbol{\Phi}$ is the modal matrix, where the columns are the eigenvectors obtained by the solving the eigenvalueeigenvector problem stated as:

$$
(K-\Omega M) \Phi=0
$$

where $\boldsymbol{\Omega}=\operatorname{diag}\left\{\omega_{1}^{2}, \omega_{2}^{2}, \ldots, \omega_{n}^{2}\right\}$ and $\boldsymbol{\Phi}=\left\{\boldsymbol{\Phi}_{1}, \boldsymbol{\Phi}_{2}, \ldots, \boldsymbol{\Phi}_{n}\right\}$ with $\boldsymbol{\Phi}_{i}=\left\{\varphi_{1 i}, \varphi_{2 i}, \ldots, \varphi_{n i}\right\}^{T}$ are the eigenvector corresponding to the eigenvalue $\omega_{i}^{2}$. Applying the previous transformation $\boldsymbol{q}=\boldsymbol{\Phi} \boldsymbol{\eta}$ to the equation of motion, one holds:

$$
M \Phi \ddot{\eta}+D \Phi \dot{\eta}+K \Phi \eta=F u
$$

Taking into account the properties of the $\Phi$ matrix and assuming proportional damping, pre-multiplying both sides of the previous equation by $\boldsymbol{\Phi}^{T}$, yields:

$$
\boldsymbol{\Phi}^{T} \boldsymbol{M} \boldsymbol{\Phi} \ddot{\boldsymbol{\eta}}+\boldsymbol{\Phi}^{T} \boldsymbol{D} \boldsymbol{\Phi} \dot{\boldsymbol{\eta}}+\boldsymbol{\Phi}^{T} \boldsymbol{K} \boldsymbol{\Phi} \boldsymbol{\eta}=\boldsymbol{\Phi}^{T} \boldsymbol{F} \boldsymbol{u}
$$


and then:

$$
\boldsymbol{I} \ddot{\boldsymbol{\eta}}+\boldsymbol{\Lambda} \dot{\boldsymbol{\eta}}+\boldsymbol{\Omega} \boldsymbol{\eta}=\left[\boldsymbol{\Phi}^{T} \boldsymbol{M} \boldsymbol{\Phi}\right]^{-1} \boldsymbol{\Phi}^{T} \boldsymbol{F} \boldsymbol{u}
$$

where $\mathbf{I}$ is the identity matrix, $\boldsymbol{\Omega}=\operatorname{diag}\left\{\omega_{1}^{2}, \omega_{2}^{2}, \ldots, \omega_{n}^{2}\right\}, \boldsymbol{\Lambda}=\operatorname{diag}\left\{2 \xi_{1} \omega_{1}, 2 \xi_{2} \omega_{2}, \ldots, 2 \xi_{n} \omega_{n}\right\}$ and the system of equations is decoupled, where $\boldsymbol{\eta}=\left\{\eta_{1}, \eta_{2}, \ldots, \eta_{n}\right\}^{T}$ is the state-space vector of the modal variables. Therefore, assuming state-space variables as $\boldsymbol{x}_{m}=\{\boldsymbol{\eta} \dot{\boldsymbol{\eta}}\}^{T}$, the following equation may be written:

$$
\begin{gathered}
\dot{\boldsymbol{x}}_{m}=\boldsymbol{A}_{m} \boldsymbol{x}_{m}+\boldsymbol{B}_{m} \boldsymbol{u} \\
\boldsymbol{y}=\boldsymbol{C}_{m} \boldsymbol{x}_{m}+\boldsymbol{D}_{m} \boldsymbol{u}
\end{gathered}
$$

where matrix $\mathbf{A}_{m}$ and $\mathbf{B}_{m}$ are:

$$
\boldsymbol{A}_{m}=\left[\begin{array}{cc}
\mathbf{0} & \boldsymbol{I} \\
-\boldsymbol{\Omega} & -\boldsymbol{\Lambda}
\end{array}\right] \quad \text { and } \quad \boldsymbol{B}_{m}=\left[\begin{array}{c}
\mathbf{0} \\
{\left[\boldsymbol{\Phi}^{T} \boldsymbol{M} \boldsymbol{\Phi}\right]^{-1} \boldsymbol{\Phi}^{T} \boldsymbol{F}}
\end{array}\right]
$$

The control forces are defined by the relation:

$$
\boldsymbol{u}=-\boldsymbol{G}_{m} \boldsymbol{x}_{m}=-\boldsymbol{G}_{m}\left\{\begin{array}{c}
\boldsymbol{\eta} \\
\dot{\boldsymbol{\eta}}
\end{array}\right\}
$$

where $\mathbf{G}_{m}$ is the gain matrix in the modal space, obtained from the solution of the Ricatti equation with the modal state matrix $\mathbf{A}_{m}, \mathbf{B}_{m}$ given previously. The functional is then written as:

$$
J_{m}=\frac{1}{2} \int_{0}^{\infty}\left(x_{m}^{T} \boldsymbol{Q}_{m} x_{m}+\boldsymbol{u}^{T} \boldsymbol{R} \boldsymbol{u}\right) d t
$$

Comparing equation (22) to the equation (9) and taking into account that $x_{m}=\{\boldsymbol{\eta} \dot{\boldsymbol{\eta}}\}^{T}=$ $\left\{\boldsymbol{\Phi}^{-1} \boldsymbol{q} \boldsymbol{\Phi}^{-1} \dot{\boldsymbol{q}}\right\}^{T}$, then one can say that:

$$
\boldsymbol{Q}_{m}=\boldsymbol{\Phi}^{-T} \boldsymbol{Q} \boldsymbol{\Phi}^{-1}
$$

Again, in this case, if one wants to minimize the output variables instead of the modal state-space variables, the function assumes the form:

$$
\text { Minimize } J_{m}=\frac{1}{2} \int_{0}^{\infty}\left(\boldsymbol{y}^{T} \boldsymbol{Q}_{m}^{*} \boldsymbol{y}+\boldsymbol{u}^{T} \boldsymbol{R} \boldsymbol{u}\right) d t
$$

where $\boldsymbol{Q}_{m}^{*}=\boldsymbol{C}^{-1} \boldsymbol{Q}_{m} \boldsymbol{C}$.

Assuming that there are some important modes to be controlled, the solution can be truncated using only these modes just by using the corresponding columns of $\boldsymbol{\Phi}$ corresponding to these modes (the matrix becomes rectangular). This generates the approximation $q_{i}=$ $\sum_{j=1}^{n \bmod } \Phi_{i, j} \eta_{j}$ (where $n \bmod$ is the number of retained modes), or in other words $\hat{\boldsymbol{q}}=\hat{\boldsymbol{\Phi}} \hat{\boldsymbol{\eta}}$. Again, assuming full state feedback control matrix $\mathbf{C}$ and $\mathbf{D}$ are defined in the same way, with $\mathbf{A}$ and $\mathbf{B}$ dimensions being reduced in the proportion of the retained modes. More details in control theory and applications to modal control can be found in Preaumont [12].

Latin American Journal of Solids and Structures 9(2012) 111 - 129 


\section{EXAMPLE OF FUZZY AND LQR NON-COLLOCATED CONTROL OF THE TRUSS STRUCTURE}

This example intends to present a benchmark problem on non-collocated vibration control of a lattice structure. It will be used to compare traditional LQR control performance with the proposed Fuzzy in a number of arrangements. So, consider the example presented by Kwon and Bang [7] for the full state feedback vibration control of a planar truss as shown by Figure 5. This is a problem with 9 degrees of freedom. There are two control forces acting on degrees of freedom 6 and 7, as shown by Figure 5. Data regarding the cross sectional areas, Young's modulus and density are also presented in the Figure 5.

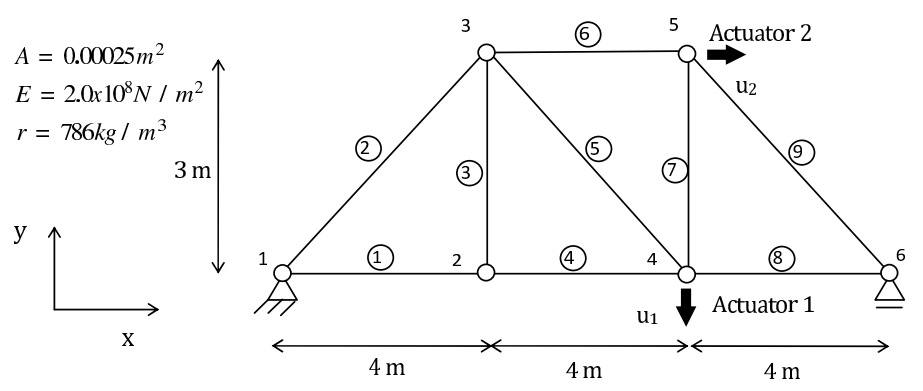

Figure 5 Sketch of the lattice structure under study [7].

The load influence matrix in this case is given by:

$$
\boldsymbol{F}=\left[\begin{array}{ccccccccc}
0 & 0 & 0 & 0 & 0 & -1 & 0 & 0 & 0 \\
0 & 0 & 0 & 0 & 0 & 0 & 1 & 0 & 0
\end{array}\right]^{T}
$$

The initial conditions for the system in this example are given by [7]:

$$
\begin{aligned}
& \boldsymbol{x}(0)=\left\{\mathrm{q}_{1}, \mathrm{q}_{2}, \mathrm{q}_{3}, \mathrm{q}_{4}, \mathrm{q}_{5}, \mathrm{q}_{6}, \mathrm{q}_{7}, \mathrm{q}_{8}, \mathrm{q}_{9}, \dot{\mathrm{q}}_{1}, \dot{\mathrm{q}}_{2}, \dot{\mathrm{q}}_{3}, \dot{\mathrm{q}}_{4}, \dot{\mathrm{q}}_{5}, \dot{\mathrm{q}}_{6}, \dot{\mathrm{q}}_{7}, \dot{\mathrm{q}}_{8}, \dot{\mathrm{q}}_{9}\right\}^{T} \\
& \boldsymbol{x}(0)=\{0.1,0.0,0.0,0.2,-0.2,0.0,0.0,0.0,0.0,0.0,0.0,0.0,0.0,0.0,0.0,0.0,0.0,0.0\}^{T}
\end{aligned}
$$

which means prescribed horizontal displacements of $0.1 \mathrm{~m}$ on node 2 , vertical displacement of $0.2 \mathrm{~m}$ on node 3 and horizontal displacement of $-0.2 \mathrm{~m}$ on node 4 .

In this example there is no damping in the system, therefore $\mathbf{D}=\mathbf{0}$. The finite element method for stiffness and consistent mass for simple truss bar elements is used to obtain these matrices. The previous formulation was implemented in Matlab and Simulink scripts so that the gain matrix $(\mathbf{G})$ can be obtained by the LQR method. The Fuzzy controller was implemented based on the Matlab's Fuzzy toolbox.

Figure 6 shows the horizontal and vertical displacements history for node 2 for the uncontrolled system. The results are the same obtained by Kwon and Bang [7].

In the following, the implemented LQR modal controller is tested with this same example. It was chosen random modes to be controlled in order to verify the correctness of the developed code. 
In Figure 7 it is compared the performance of the LQR controller and the Modal LQR controller using just the 1st. mode and using the first 4 modes (1st,2nd,3rd,4th) in terms of horizontal and vertical displacements on node 2. Figure 8 shows the horizontal and vertical displacement Power Spectral Densities for node 2 for uncontrolled and controlled system using modal LQR (just $1^{\text {st }}$ mode and $1^{\text {st }}$ to $4^{\text {th }}$ modes). Figure 9 shows the control forces Power Spectral Densities for nodes 4 and 5 comparing uncontrolled and controlled system using modal LQR ( $1^{\text {st }}$ and $1^{\text {st }}$ to $4^{\text {th }}$ modes). The results shows the effectiveness of conrolling the desirable modes by noticng the decrease in the PSD amplitudes in the corresponding frequencies.was equal to the results presented by Kwon and Bang [7].

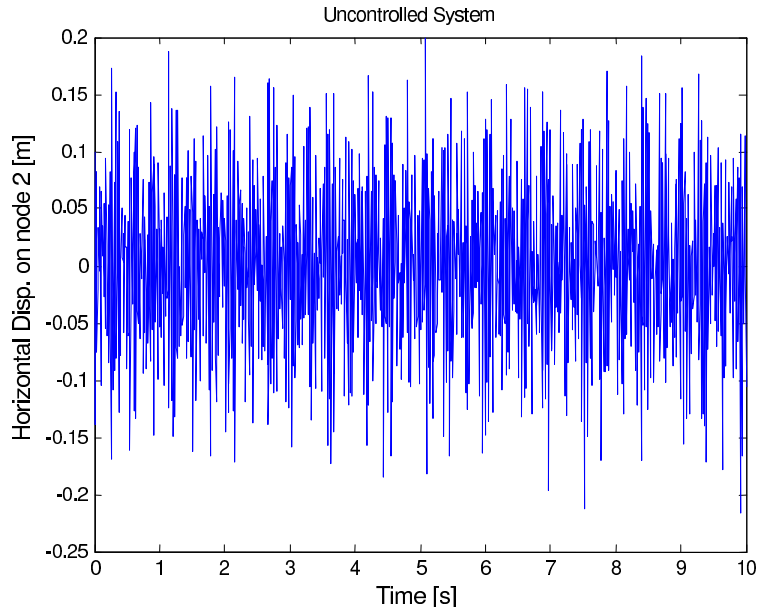

(a)

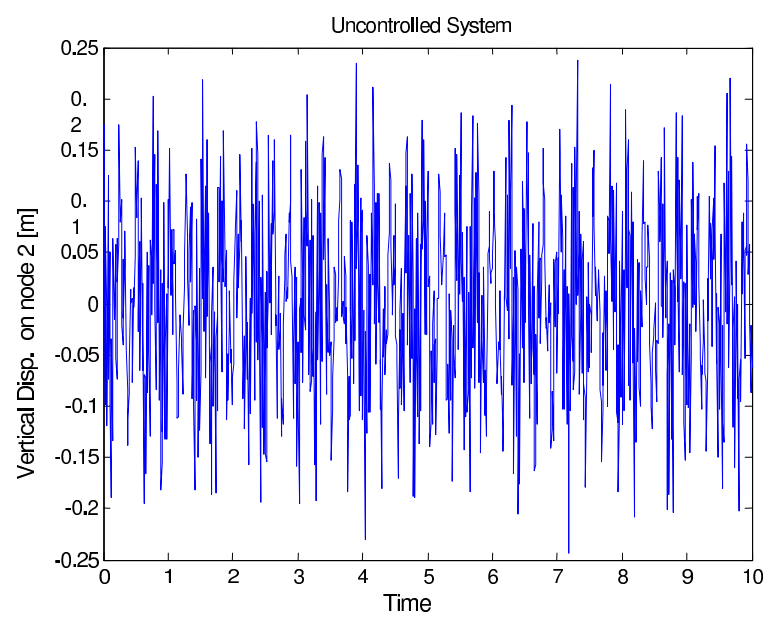

(b)

Figure 6 (a) Hor. and (b)Vert. displacement history for node 2 without control.

\subsection{Qualitative estimation of gain matrix}

Starting from the uncoupled equation of motion in modal space, one has:

$$
\boldsymbol{I} \ddot{\boldsymbol{\eta}}+\boldsymbol{\Lambda} \dot{\boldsymbol{\eta}}+\boldsymbol{\Omega} \boldsymbol{\eta}=\left[\boldsymbol{\Phi}^{T} \boldsymbol{M} \boldsymbol{\Phi}\right]^{-1} \boldsymbol{\Phi}^{T} \boldsymbol{F u}
$$

Using the concept of Pseudo-Inverse $\left(\boldsymbol{J}^{+}=\boldsymbol{J}^{T}\left(\boldsymbol{J} \boldsymbol{J}^{T}\right)^{-1}\right)$, one can rewrite the previous equation as:

$$
\begin{aligned}
& \boldsymbol{u}=\boldsymbol{P}_{\text {inertia }}+\hat{\boldsymbol{G}}_{m} \boldsymbol{x}_{m}=\left[\left[\boldsymbol{\Phi}^{T} \boldsymbol{M} \boldsymbol{\Phi}\right]^{-1} B^{T} \boldsymbol{F}\right]^{+} \boldsymbol{I} \ddot{\boldsymbol{\eta}}+\hat{\boldsymbol{G}}_{m} \boldsymbol{x}_{m} \\
& =\left[\left[\boldsymbol{\Phi}^{T} \boldsymbol{M} \boldsymbol{\Phi}\right]^{-1} \boldsymbol{\Phi}^{T} \boldsymbol{F}\right]^{+} \boldsymbol{I} \ddot{\boldsymbol{\eta}}+\left[\left[\boldsymbol{\Phi}^{T} \boldsymbol{M} \boldsymbol{\Phi}\right]^{-1} \boldsymbol{\Phi}^{T} \boldsymbol{F}\right]^{+}[\boldsymbol{\Omega} \boldsymbol{\Lambda}]\left\{\begin{array}{c}
\boldsymbol{\eta} \\
\dot{\boldsymbol{\eta}}
\end{array}\right\}
\end{aligned}
$$

The second part on the right side of the equation gives relevant information related to the control forces, modal displacements and velocities. This part can be used as a first approx-

Latin American Journal of Solids and Structures 9(2012) $111-129$ 


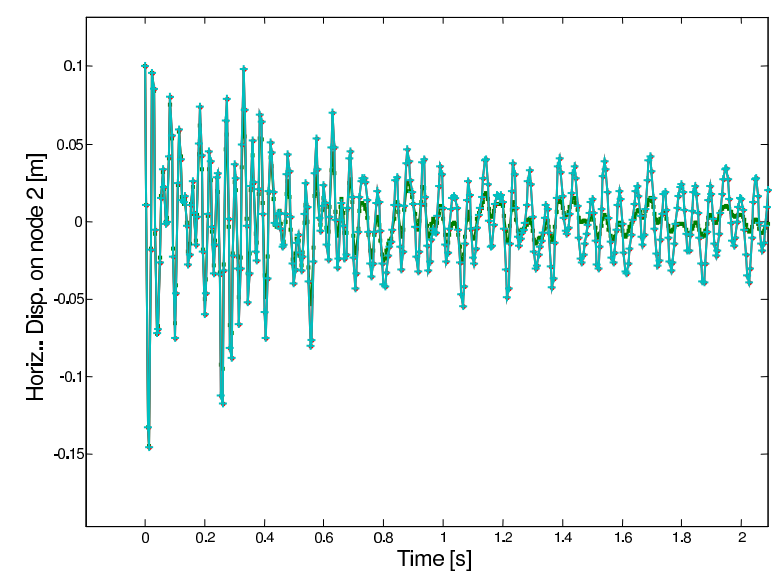

(a)

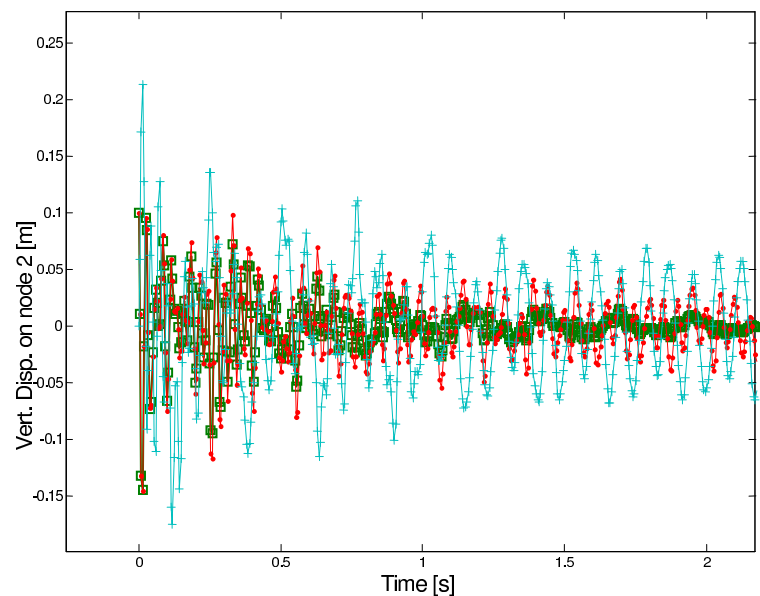

(b)

Figure 7 (a) Horiz. and (b)Vert. displacements history for node 2 ( $\square)$ LQR, (o) modal control (1 $1^{\text {st }}$ mode), $(+)$ modal control ( $1^{\text {st }}$ to $4^{\text {th }}$ mode).

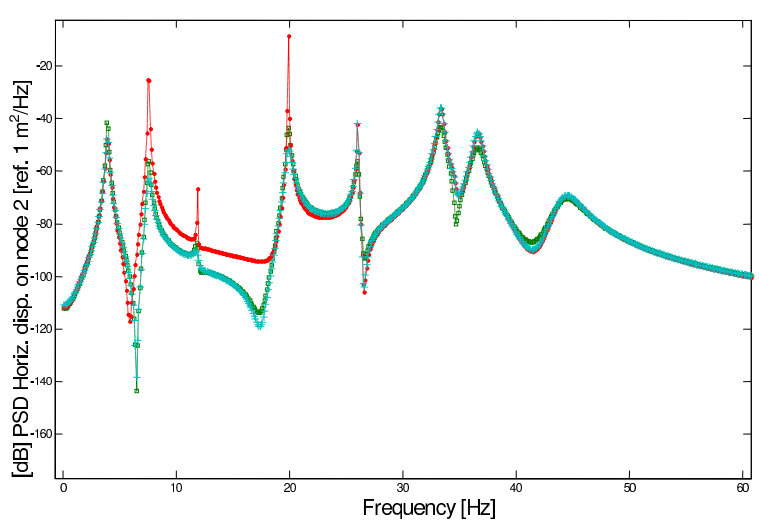

(a)

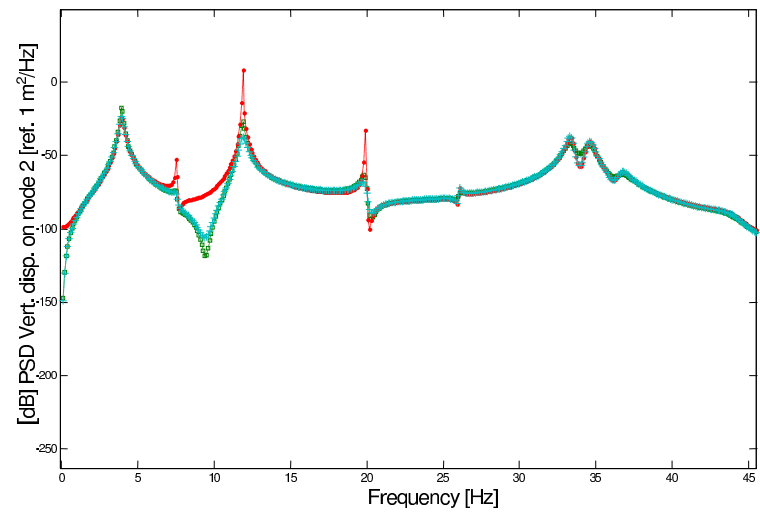

(b)

Figure 8 (a) Horiz. and (b)Vert. PSD of displacement history (dB) for node 2 ( $\square$ )LQR, (o) modal control( $1^{s t}$ mode $),(+)$ modal control $\left(1^{s t}\right.$ to $4^{\text {th }}$ mode $)$.

imation of the gain matrix that will later be used by the Fuzzy controller and added to the inertial forces.

Similarly, this approach can be implemented at the level of variables in real space. Starting from the equation (27), this yields:

$$
\begin{aligned}
\boldsymbol{u} & =\boldsymbol{P}_{\text {inertia }}+\hat{\boldsymbol{G}} \boldsymbol{x}=\boldsymbol{F}^{+} \boldsymbol{M} \ddot{\boldsymbol{q}}+\hat{\boldsymbol{G}} \boldsymbol{x} \\
& =\boldsymbol{F}^{+} \boldsymbol{M} \ddot{\boldsymbol{q}}+\boldsymbol{F}^{+}\left[\begin{array}{ll}
\boldsymbol{K} & \boldsymbol{D}
\end{array}\right]\left\{\begin{array}{c}
\boldsymbol{q} \\
\dot{\boldsymbol{q}}
\end{array}\right\}
\end{aligned}
$$




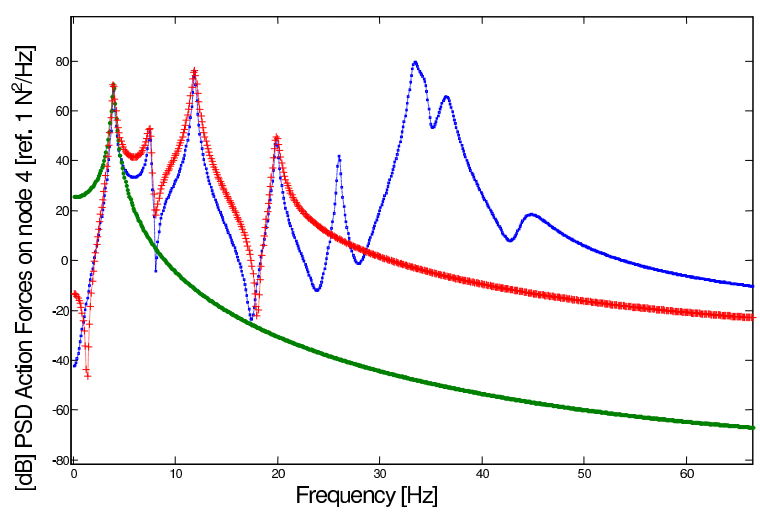

(a)

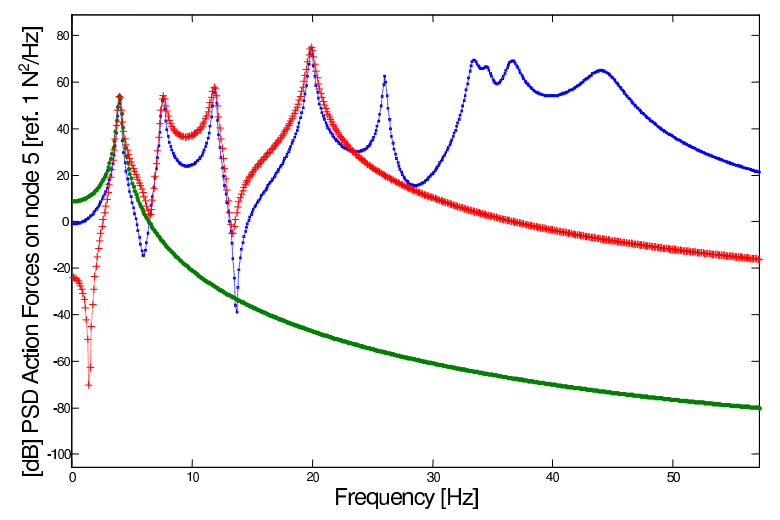

(b)

Figure 9 (a) Node 4 and (b) node 5 PSD of control forces (dB) ( $\square$ )LQR, (o) modal control( $1^{\text {st }}$ mode), $(+)$ modal control ( $1^{\text {st }}$ to $4^{\text {th }}$ mode).

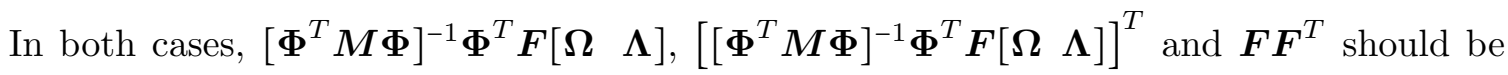
non-singular in order to the pseudo-inverse be evaluated.

Using this estimated gain matrix, one can apply the scalar gain (g) that comes from the Fuzzy controller. This control output should multiply the entire estimated gain matrix. As input, this controller may have the modal state variables of an observer to estimate the states of the modal system.

$$
\begin{gathered}
\boldsymbol{u}=\boldsymbol{P}_{\text {inertia }}+g \hat{\boldsymbol{G}} \boldsymbol{x} \text { or } \\
\boldsymbol{u}=\boldsymbol{P}_{\text {inertia }}+g \hat{\boldsymbol{G}}_{m} \boldsymbol{x}
\end{gathered}
$$

At this point, it is worth to say that the estimates of the gain matrix should be in a size appropriate to deal with the respective number of used variables (whether just some, using modal state space variables, whether a large number, using state space in original space).

The Fuzzy controller constructed is composed of two entries " $e$ " and " $d e$ " that represents than $e=0-\eta$ and $\dot{\eta}=0-\dot{e}$ (both related to a reference value of zero). In the case of controlling more than one mode, it may be created new controllers for each additional mode to be controlled.

For all membership function, the error, it derivative (inputs for Fuzzy Controller) and the scale that will multiply the gain matrix (output of the Fuzzy controller) are of triangular type. In order to define the limits of effectiveness of the input variables it was chosen values in the interval $[-2,2]$ and for the output variable was chosen values in the interval $[0,2]$. For the input variables it was assumed 3 fuzzy sets: $\mathrm{N}$ (Negative), Z (Zero) and P (positive), being Z centred on the interval $[-2,2]$ and the other two sets centred on the boundaries of the interval. For the output variables it was chosen 5 fuzzy sets, namely: RL (Reduced Large), RM (Reduced Medium), U (Unit), AM (Amplified Medium) and AL (Amplified Large), equally spaced in the interval $[0,2]$ and the extreme sets, focusing on the limits of the range. The rule base was 
establishedtaking into account a simple PD controller as shown in Figure 1.4. Figures 10 and 11 show the mentioned membership functions.

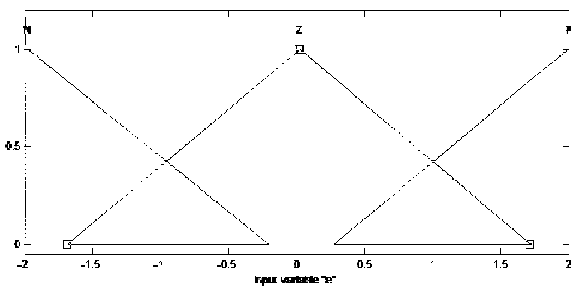

(a)

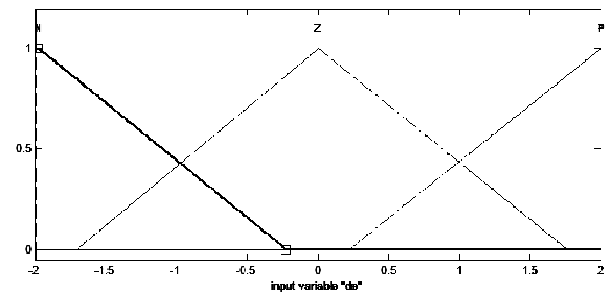

(b)

Figure 10 Membership functions and Fuzzy sets used for inputs (a) $e$ and (b) de.

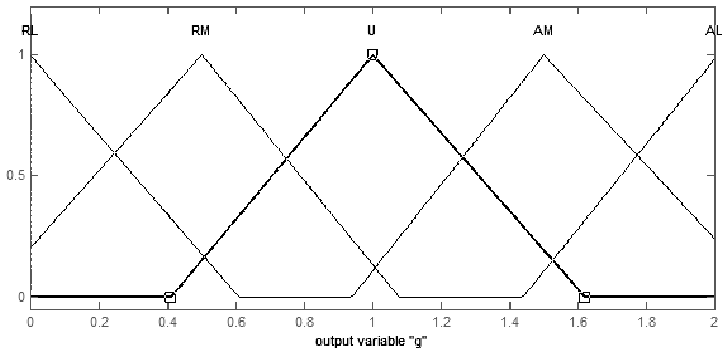

Figure 11 Membership functions and Fuzzy sets for the output $g$.

Figure 12 shows the horizontal and vertical PSD for displacements on node 2 using a simple LQR, a Fuzzy-LQR ( $1^{\text {st }}$ mode), a Fuzzy with $\mathbf{G}_{m}$ estimated ( $1^{\text {st }}$ mode) and a Fuzzy- complete $\mathbf{G}$ estimated(1 $1^{\text {st }}$ mode). It can be noticed that the proposed Fuzzy controllers is as effective as the LQR controller.

Figure 13 shows the PSD of control forces using a simple LQR, a Fuzzy-LQR ( $1^{\text {st }}$ mode), a Fuzzy with $\mathbf{G}_{m}$ estimated ( $1^{\text {st }}$ mode) and a Fuzzy- complete $\mathbf{G}$ estimated( $1^{\text {st }}$ mode).

\section{COMPARISONS OF PROPOSED CONTROLLERS IN THE PRESENCE SYSTEM'S PARAMETERS CHANGE}

\subsection{Global mass change of the whole structure}

It is intended to investigate the performance of the LQR and Fuzzy controllers when used in a system that has some parameters changed. The idea is to check the robustness of each of these models against the presence of changes on these parameters. It is expected that the LQR controller has reduced its performance in attenuating vibration, since the gain matrix is fixed and defined beforehand according to the characteristics of the system. Moreover, it is expected that the controller based on fuzzy logic behaves in a more robust way. Even though based on system parameters, the fuzzy controller allows changing his gain in proportion to modal displacement and velocity error. 


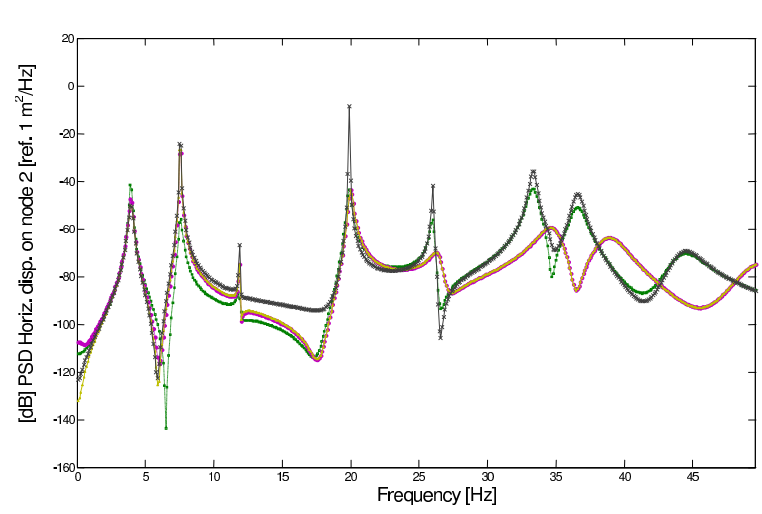

(a)

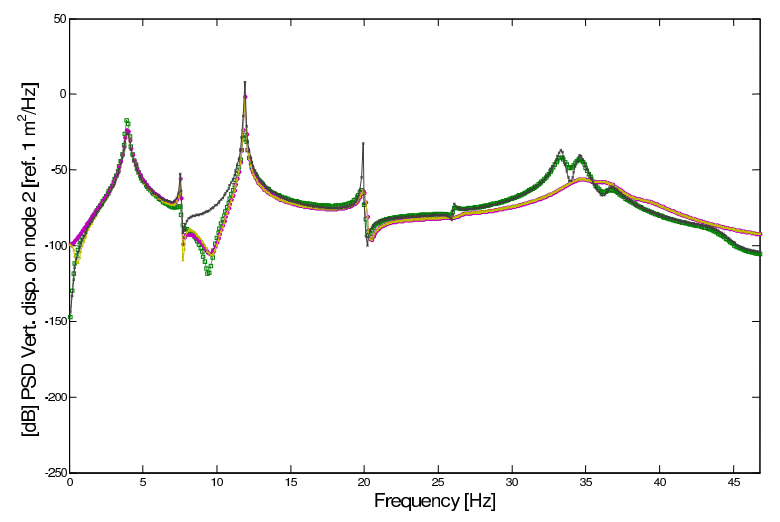

(b)

Figure 12 (a)Horiz. and (b)Vert. PSD of displacement history (dB) for node 2 ( $\square$ )LQR, (o)Fuzzy-LQR (1 ${ }^{\text {st }}$ mode), $(\Delta)$ Fuzzy- $\mathbf{G}_{m}$ estimated(1 ${ }^{\text {st }}$ mode), $(\times)$ Fuzzy- $\mathbf{G}$ estimated ( $1^{\text {st }}$ mode).

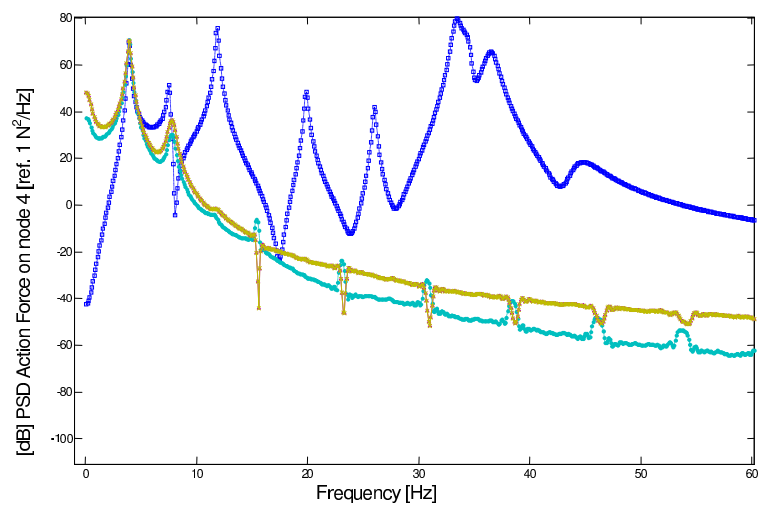

(a)

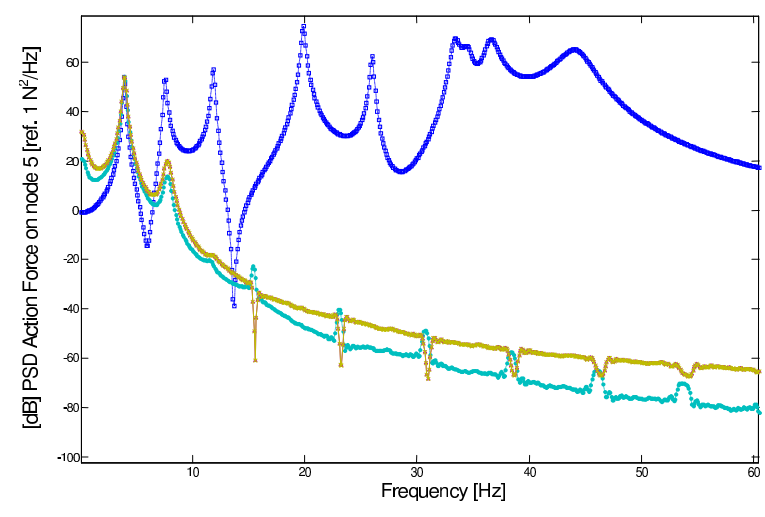

(b)

Figure 13 PSD of control force history (dB) on (a) Node 4. and (b)Node 5 ( $\square$ )LQR, (o)Fuzzy-LQR (1 ${ }^{\text {st }}$ mode), $(\Delta)$ Fuzzy- $\mathbf{G}_{m}$ estimated ( $1^{\text {st }}$ mode), $(\times)$ Fuzzy- $\mathbf{G}$ estimated $\left(1^{\text {st }}\right.$ mode).

In all tests, it was obtained in advance the parameters of the Fuzzy and LQR controllers and later they were employed in a closed-loop control on a system with the mass parameters modified. In this example, the mass matrix was increased by $100 \%$. In these tests, just the $4^{\text {th }}$ mode was controlled. The 4th mode was arbitrarily chosen to be controlled, though it was an important mode in terms of energy like $1^{\text {st }}$., $2^{\text {nd }}$. and $3^{\text {rd }}$. as indicated by the displacement PSD (Figure 15) of the uncontrolled structure. Figure 14 shows the horizontal and vertical PSD of displacement on node 2 using controllers of type Fuzzy-Gm estimated ( $4^{\text {th }}$ mode), LQR ( $4^{\text {th }}$ mode), Modified system without control and Fuzzy-LQR Gm estimated ( $4^{\text {th }}$ mode). 


\subsection{Stiffness and mass change on single sites of the structure}

In this example it is intended to investigate the performance of the controllers faced to localized changes in the structure. So, it was attached a mass of $1 \mathrm{~kg}$ to node 3 and reduced $50 \%$ of the member 4 stiffness. For sake of comparison it was chosen to maintain no damping as in the previous examples.

Figure 15 shows the horizontal and vertical PSD displacements on node 2 for the modified system without control and with control (LQR, Fuzzy-LQR and Fuzzy $\mathrm{G}_{m}$ estimated)

Figure 16 shows the same comparisons on node 4 and 5 for the PSD of control forces.

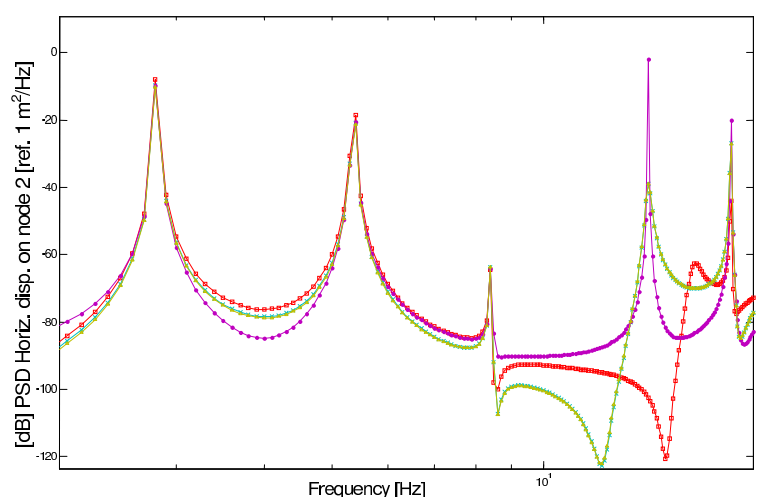

(a)

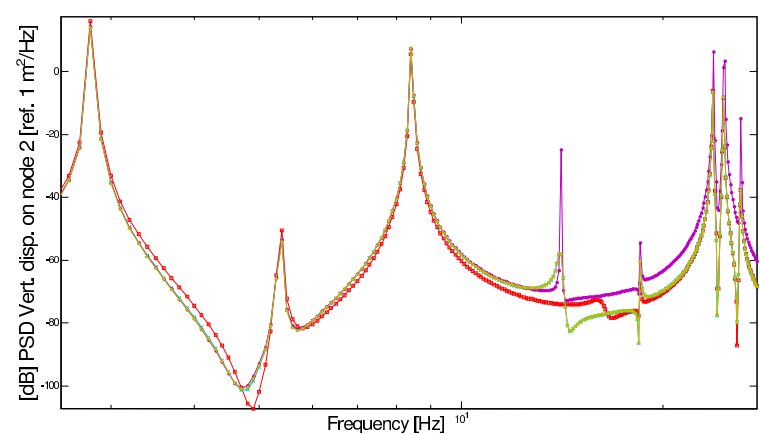

(b)

Figure 14 (a)Horiz. (b)Vert. PSD of displacements history (dB) on node 2. ( $\square$ )Fuzzy-Gm estimated (4th mode), $(\times)$ LQR $\left(4^{\text {th }}\right.$ mode), $(\cdot)$ Modified system without control, $(\Delta)$ Fuzzy-LQR Gm estimated $\left(4^{\text {th }}\right.$ mode).

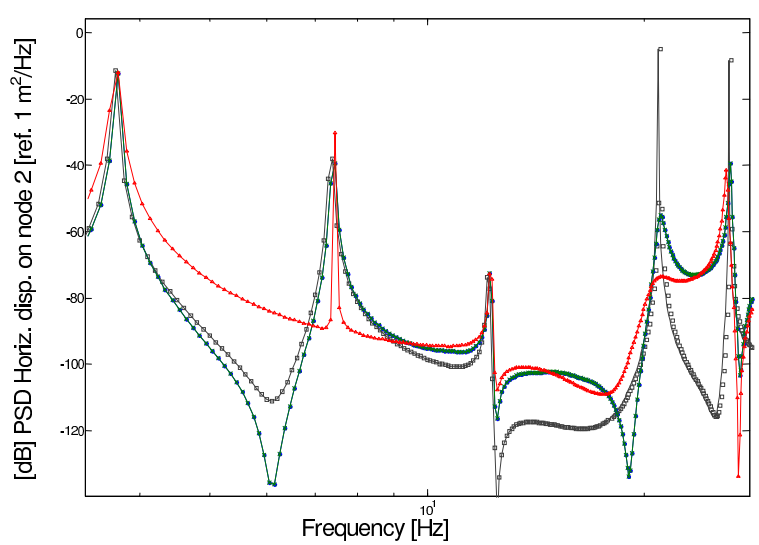

(a)

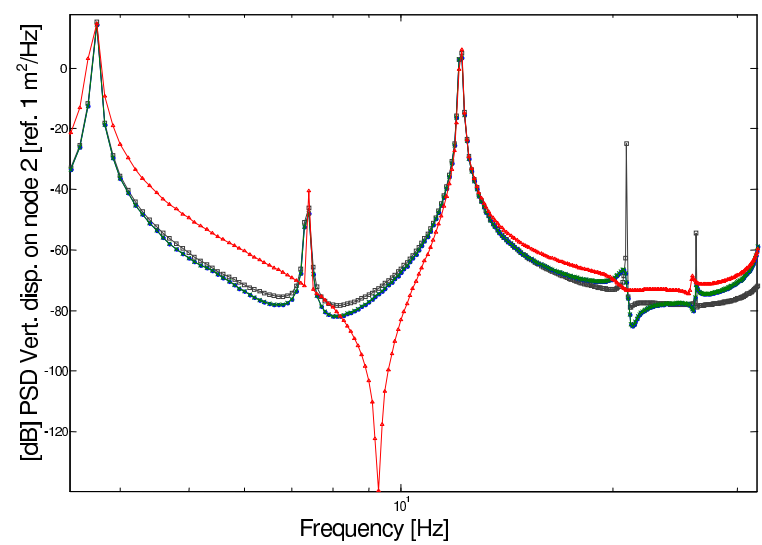

(b)

Figure 15 (a)Horiz. and (b)Vert. PSD of displacements history (dB) on node 2 ( $\square$ ) Modified System without control, (.) LQR ( $4^{\text {th }}$ mode), $(\times)$ Fuzzy-LQR( $4^{\text {th }}$ mode), $(\Delta)$ Fuzzy-Gm estimated( $4^{\text {th }}$ mode). 


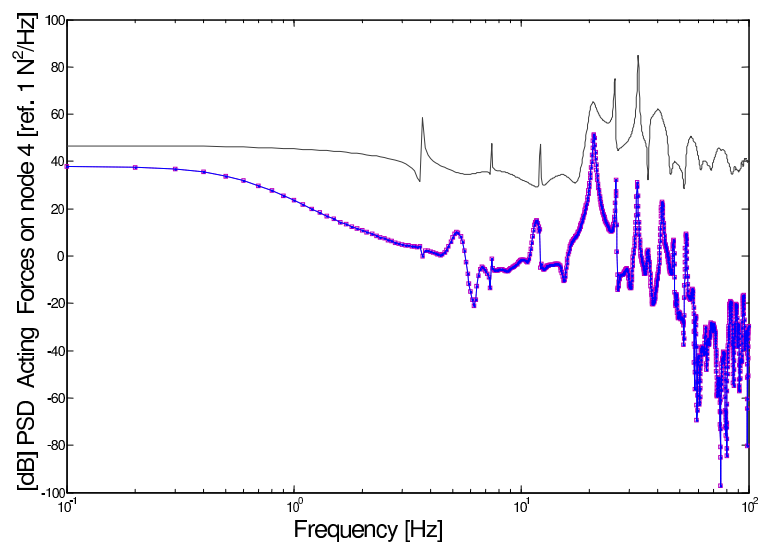

(a)

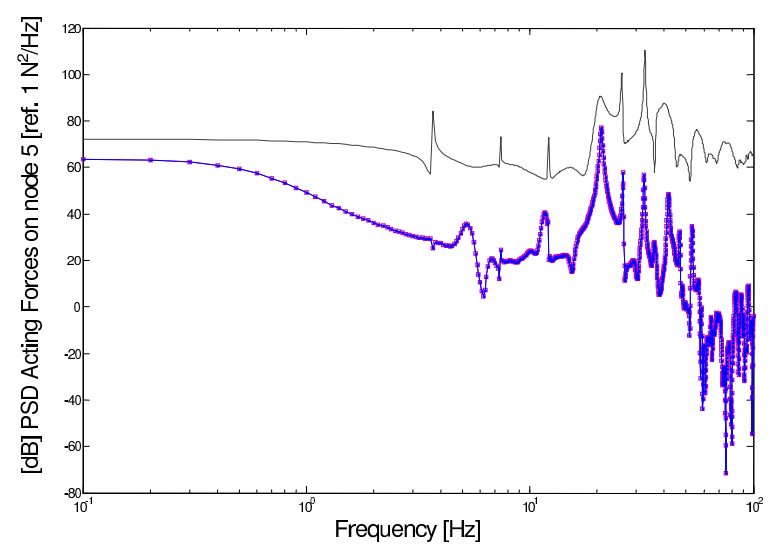

(b)

Figure 16 PSD of control force history $(\mathrm{dB})$ on (a)node 4 and (b)node 5. (口)LQR (4 ${ }^{\text {th }}$ mode) modified system, (.)Fuzzy-LQR ( ${ }^{\text {th }}$ mode), (-)Fuzzy-Gm estimated ( ${ }^{\text {th }}$ mode).

\section{FINAL REMARKS}

Based on the results, it was observed that the Fuzzy controller performance was equivalent to the LQR controller and sometimes outperformed this traditional controller. It was presented three ways to work with the Fuzzy controller, namely: (a) Fuzzy supervisory controller of the gain matrix of the LQR control $(\boldsymbol{G})$, (b) Fuzzy controllers in an amount equal to the modes to be controlled in the modal space $\left(\hat{\boldsymbol{G}}_{m}\right)$, (c) Fuzzy controller with gain matrix estimated in real space $(\hat{\boldsymbol{G}})$.

Among the proposals, that which presented better results was the suggestion (b) designing a Fuzzy Controller for each mode to be controlled and gain matrix estimated in the modal space since it is not necessary to solve the Ricatti equation and the number of variables is reduced. The suggestion of designing a supervisory Fuzzy controller for the LQR control showed little improvement in performance when compared to the simple LQR controller.

Regarding the performance of Fuzzy controllers compared to variations of the parameters of the system, it was expected a poor performance of the LQR controller, as the gain matrix is fixed. This behavior was observed in the two tests with a variation of the total mass of the structure and the locally change in mass and stiffness, noticing that the Fuzzy controller outperformed the LQR in vibration suppression in the presence of uncertainties (Figure 14 and 15). However PSD graphs for control forces shows values of control forces higher than those applied by the LQR controller, indicating a greater energy use (Figure 16). In the analysed cases, it was noticed that the suggestion of the Fuzzy controller with estimated gain matrix added to the inertia forces, may increase vibration, in the event of changes in system parameters, in frequency ranges not observed in the system without control.

Future research will focus on the use of different membership functions and aggregation rules (TS, for example). The use of independent controllers in collocated systems working as 
SISO (which ensures unrestricted stability control) and experimental tests of the developed controllers are also subject of future researches.

Acknowledgements The financial support of this research by CNPq and CAPES (Brazilian Councils for Research and Development) is thankful.

\section{References}

[1] M. A. Ahmad. Vibration reduction technique using LQR and PD-type fuzzy logic controller: a comparative study. In Proceedings of the international Conference on Electronic Design, Penang, Malaysia, 2008.

[2] A. I. Al-Odienat and A. A. Lawama. The advantages of pid fuzzy controllers over the conventional types. American Journal of Applied Sciences, 5(6):653-658, 2008.

[3] N. D. Assimakis, D. G. Lainiotis, S. K. Katsikas, and F. L. Sanida. A survey of recursive algorithms for the solution of the discrete time ricatti equation. nonlinear analysis theory, method and applications. Proceedings of the 2nd World Congress of nonlinear Analysis, 30(4):2409-2420, 1997.

[4] K.-M. Choi, S.-W. Cho, D.-O. Kim, and I.W. Lee. Active control for seismic response reduction using modal-fuzzy approach. International Journal of Solids and Structures, (42):4779-4794, 2005.

[5] V. Dimitrov and B. Hodge. Why fuzzy logic needs the challenge of social complexity? with fuzzy logic in the new millennium. Richmond, 2000. Publ. UWS.

[6] J. Jantzen. Foundations of fuzzy control. Wiley, 2007.

[7] Y. W. Kwon and H. Bang. The finite Element method using Matlab. CRC Press, 1996.

[8] C. C. Lee. Fuzzy logic in control systems: fuzzy logic controller - Part I. IEEE Transaction on systems, man and cybernetics, 20(2):440-418, 1990.

[9] E.H. Mamdani and S. Assilian. An experiment in linguistic synthesis with a fuzzy logic controller. International Journal of Man-Machine Studies, 7(1):1-13, 1975.

[10] K. M. Passino and S. Yurkovich. Fuzzy Control. Addison-Wesley Longman Inc., 1997.

[11] W. Pedrycz and F. Gomide. An Introduction to Fuzzy Sets. The MIT Press, 1998.

[12] A. Preaumout. Vibration Control of Active Structures: An introduction. Kluwer academic publishers, 2nd edition, 2002

[13] D.E. Seborg and M. A. Henson. An internal model control strategy for nonlinear systems. AIChE Journal, 37(7), 1991.

[14] M. Sugeno. Industrial applications of fuzzy control. Elsevier Science Pub. Co., 1985.

[15] T. Takawa, F. Takehito, and N. Koichiro. Fuzzy control of vibrations of a smart CFRP laminated beam. Smart Materials and Structures, (9):215-219, 2000.

[16] T-L. Teng, C-P. Peng, and C. Chuang. A study on the application of fuzzy theory to structural active control. Comp. Methods Appl. Mech. Engineering, (189):439-448, 2000.

[17] L. A. Zadeh. Fuzzy sets. Information and Control, (8):338-353, 1965.

[18] C-S. Zhao, Zhu S-J., and Q-W. He. Fuzzy PID control method for two stage vibration isolation system. Journal of Theoretical and Applied Mechanics, 45(1):171-177, 2007. 


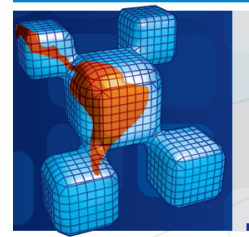

\section{ERRATUM TO:}

Fuzzy Logic for Structural System Control, vol. 9, n. 1, p. 111-129, 2012.

This paper is single authored by Herbert Martins Gomes. The other originally cited co-author, Cesar Miguel Almeida Vasques, states that has no contribution to the above mentioned article.

Marcílio Alves

Editor-in-Chief

Rogério Marczak and Heraldo da Costa Mattos Associate Editors

Latin American Journal of

Solids and Structures ww. lajss.org 